\title{
PKM Sosialisasi Dampak Gadget, Bahaya Penyalahgunaan Narkoba dan Pergaulan Bebas
}

\author{
Lensoni ${ }^{1}$ \\ Fakultas Kesehatan Masyarakat, Universitas Abulyatama \\ lensoni@abulyatama.ac.id \\ Meri Lidiawati² \\ Fakultas Kedokteran, Universitas Abulyatama, merilidyawati_fk@abulyatama.ac.id \\ Noeroel Arham ${ }^{3}$ \\ Mahasiswa Fakultas Kesehatan Masyarakat, Universitas Abulyatama, \\ arhamnoeroe190@gmail.com \\ Erna Savitri ${ }^{4}$ \\ Mahasiswa Fakultas Kesehatan Masyarakat, Universitas Abulyatama, \\ ernasafitri89@gmail.com \\ Cut Rahmawati ${ }^{5}$ \\ Program Studi Teknik Sipil, Universitas Abulyatama, cutrahmawati@abulyatama.ac.id
}

\begin{abstract}
Abstrak
Perkembangan teknologi telah membuat perubahan gaya hidup manusia yang semakin kompleks dimana segala sesuatu harus dapat dilakukan secara cepat. Salah satu teknologi yang canggih dan fleksible adalah gadget. Gadget yang sifatnya sebagai mobile human yang dinamis memberi pengerauh besar pada gaya hidup masyarakat modern. Kecanggihan teknologi telah membawa dampak besar pada remaja. Dunia remaja sangat rentan terhadap pengaruh buruk teknologi dimana semua hal dapat dengan mudah didapati remaja dalam gadget. Pengaruh buruk gadget pada remaja adalah narkoba dan pergaulan bebas. Dengan adanya gadget akses pertemanan terbuka lebar dan akses pada konten-konten berbau pornografi-pun dengan mudah didapat. Atas dasar keinginan untuk menyelamatkan generasi bangsa maka PKM ini dilakukan pada remaja. Sasaran PKM adalah remaja berusia 12 sampai 14 tahun pada SMP Abulyatama. Kegiatan ini bertujuan untuk meningkatkan pengetahuan siswa/i di SMP Abulyatama melalui pendidikan pengetahuan tentang dampak penggunaan gadget, bahaya penyalahgunaan narkoba dan pergaulan bebas. Kegiatan dilakukan dengan metode ceramah dan diskusi. Pendekatan dilakukan dengan mencari permasalahan siswa/i dan memberi solusi. Permasalahan siswa/i didapat pada saat diskusi kemudian pemecahan masalah disajikan pada akhir kegiatan. Hasil kegiatan menunjukkan siswa/i sudah paham akan bahaya gadget bagi pembentukan karakter mereka dan bersemangat untuk menginformasikan hasil dari kegiatan kepada teman-teman lain di luar sekolah. Sebagai lembaga pendidikan yang sangat berdekatan dengan lingkungan mereka, bimbingan dan dukungan pada kegiatan remaja diharapkan terus dilakukan oleh Universitas Abulyatama.
\end{abstract}

Kata Kunci: gadget, narkoba, pergaulan bebas, gaya hidup

\section{Abstract}

The development of technology has made changes in human lifestyles which is increasingly complex where everything must be done quickly. One of the sophisticated and flexible 
technology is a gadget. Gadgets as the dynamic mobile human have a big influence on the lifestyle of modern society. Moreover, sophisticated technology has had a big impact on teenagers. The world of adolescents is very vulnerable to the adverse influence of technology where all things can easily be found by teenagers in gadgets. The most adverse influences of gadgets on teenagers are drugs and promiscuity. With the presence of gadgets, the friendship access opens widely and the access of pornographic content is obtained easily. Based on the eagerness to save the nationE\#39; seneration, therefore the Community Service was carried out in the adolescents. Moreover, the target of Community Service was the adolescents who are aged 12 to 14 years at Abulyatama Junior High School. The aim of the Community Service was to increase the knowledge of students of Abulyatama Junior High School through the educational knowledge about the impact of using gadgets, the dangers of drug abuse and promiscuity. The activities were carried out by giving lectures and discussions. The approach was done by finding studentsE\#39; problems and giving solutions. The student problems were obtained during the discussion, then the problem solving was presented at the end of the activity. The results of the activity showed that the students had understood the dangers of gadgets for their character building. In addition, they were eager to inform the results of activities to the other friends outside of their school. As the educational institution that is very close to their environment, Abulyatama University is expected to continue to give guidance and support for the adolescents' activities.

Keywords: gadgets, drugs, promiscuity, lifestyle

\section{Pendahuluan}

Kegiatan pengabdian kepada masyarakat ini dilatarbelakangi oleh perkembangan teknologi yang sudah memberikan pengaruh buruk pada remaja. Kecangihankecanggihan teknologi yang hadir dapat menimbulkan banyak dampak dalam kehidupan remaja, baik itu dampak yang positif maupun dampak negatif. Para pengguna gadget sebaiknya menyadari akibat-akibat tersebut, gadget dapat menguntungkan manusia, namun juga dapat mendegredasi manusia dari yang semestinya. Remaja diharapkan bersikap cerdas dalam menggunakan gadet agar hidup dengan gadget lebih baik daripada hidup tanpanya. Keterbukaan informasi membuat dunia remaja sangat rentan oleh pergaulan bebas dan narkoba, karena terlalu bebasnya, seringkali kegiatan mereka sehari-hari tidak terkontrol baik oleh pihak keluarga, sekolah maupun masyarakat. Jika hal semacam itu berlanjut bukan tidak mungkin akan banyak hal negatif yang akan muncul.

Penyebaran narkoba pada kalangan remaja di Kabupaten Aceh Besar sudah tidak terkendali lagi. Bandar-bandar narkoba sudah banyak yang ditangkap (Misran, 2019). Hal tersebut membuat banyak orang tua merasa resah dan khawatir atas perkembangan anaknya. Remaja pada dasarnya tahu bahwa sebenarnya narkoba itu berbahaya bagi mereka, namun tetap saja ada yang menggunakannya dengan alasan coba-coba dan ikut pergaulan. Semua kegiatan penyebaran dan mencari teman untuk mencoba narkoba dilakukan melalui handphone (HP). 
Kenyataan lain yang dihadapi remaja di Aceh adalah pergaulan bebas (Molida, 2018) (Kompas, 2014). Kenyataan ini sangat mengkhawatirkan, karena remaja adalah generasi penerus bangsa. Melihat berbagai fakta yang terjadi saat ini, tidak sedikit para pemuda pemudi yang terjerumus ke dalam lembah pergaulan bebas (free sex), disebabkan terlalu jauhnya kebebasan mereka dalam bergaul. Faktor utama masalahnya adalah kurangnya pemahaman masyarakat saat ini terhadap batas-batas pergaulan antara pria dan wanita. Disamping itu didukung oleh arus modernisasi yang telah menglobal dan lemahnya benteng keimanan mengakibatkan masuknya budaya asing tanpa adanya seleksi.

Secara umum kegiatan sosialisai ini bertujuan untuk meningkatkan pengetahuan siswa/i di SMP Abulyatama melalui pendidikan, pengetahuan tentang dampak penggunaan gadget, bahaya penggunaan narkoba dan pergaulan bebas. Secara spesifik tujuan kegiatan ini sebagai berikut.

a) Memberikan pengetahuan pada siswa/i SMP Abulyatama tentang makna gadget, narkoba dan pergaulan bebas.

b) Memberikan pendidikan siswa/i SMP Abulyatama tentang waktu penggunaan gadget sesuai batasan usia.

c) Memberikan pengetahuan tantang berbagai jenis dan bentuk-bentuk dari narkoba, dampak negatif penggunaan narkoba tersebut.

d) Memberikan pendidikan dan pengetahuan pada siswa/i di SMP Abulyatama tentang dampak pergaulan bebas.

e) Mengajak siswa/i untuk menggunakan gadget sesuai dengan batasan usia

f) Mengajak siswa/i untuk tidak mendekati atau menggunakan narkoba sama sekali, cukup untuk dikenal dan dipahami.

\section{Manfaat Kegiatan}

Hasil kegiatan pengabdian pada masyarakat ini memberikan kontribusi positif dalam peningkatan pengetahuan siswa/i di SMP Abulyatama Secara eksplisit manfaat kegiatan ini adalah sebagai berikut:

a) Siswa/i yang terlibat dalam kegiatan ini memperoleh tambahan wawasan tentang gadget, bahaya peyalahnggunaan narkoba dan pergaulan bebas.

b) SMP Abulyatama memperoleh peluang untuk memiliki sumber daya manusia yang berkualitas.

c) Siswa/i SMP Abulyatama dapat menjadi penyebar informasi kepada teman-teman lain yang berada di luar lingkungan sekolah.

Berbagai penelitian telah dilakukan terkait bahaya gadget seperti (Chusna, 2017) menyatakan bahwa penggunaan gadget yang berlebihan akan berdampak buruk bagi anak. Dengan gadget, anak akan menjadi lebih mudah marah, pemberontak, malas mengerjakan rutinitas sehari-hari serta tidak peduli pada lingkungan sekitar. (Anggraeni \& Hendrizal, 2018) menyatakan bahwa dampak positif dari gadget adalah mempermudah mencari informasi dan alat komunikasi yang handal. Dampak negatifnya adalah menghambat proses interaksi siswa terhadap sesama, berakibat buruk pada perilaku sosial dan sikap siswa, serta mengabaikan lingkungan sekitar. Solusi yang ditawarkan adalah pembatasan serta arahan dalam 
penggunaan gadget. (Witarsa, Hadi, Nurhananik, \& Haerani, 2018) menyimpulkan bahwa gadget tidak hanya mempengaruhi pola pikir atau perilaku orang dewasa, tetapi juga mempengaruhi perilaku anak-anak. Bermain gadget dalam waktu yang lama dan setiap hari, dapat membuat anak berkembang ke arah pribadi yang antisosial.

Narkoba (narkotika, psikotropika dan bahan-bahan zat adiktif lainnya) menurut (Eleanora, 2011) dapat membahayakan kehidupan manusia, jika dikonsumsi dengan cara yang tidak tepat, bahkan dapat menyebabkan kematian. Dampak negatif narkoba sangat luas, baik secara fisik, psikis, ekonomi, sosial budaya hankam, dan lain sebagainya. Dalam penelitian (Pina \& Soedirham, 2015) menyatakan pemerintah dan lingkungan pendidikan sangat berperan dalam mencegah bahaya narkoba. Usaha pemerintah dalam melaksanakan program pencegahan penyalahgunaan narkoba yang perlu dilakukan diantaranya sosialisasi, kurikulum integrasi anti narkoba, pembentukan konselor sebaya, dan pembentukan kader pemuda anti narkoba.

Hasil penelitian (Kasim, 2014) menunjukkan bahwa pergaulan bebas di Aceh yang tertinggi terjadi di Kota Lhokseumawe, dengan tingkat keterlibatan pelajar mencapai 70 persen. Lhokseumawe menduduki peringkat pertama terbanyak pelaku seks pranikah dikalangan pelajar, menyusul Banda Aceh sebanyak 50 persen di ikuti oleh kabupaten/kota lainya. Dampak dari seks berisiko adalah kasus kehamilan tidak diinginkan, penyakit kelamin menular, HIV/AIDS, serta aspek psikologi dan sosial lainya.

\section{Metode}

Kegiatan dilakukan dengan metode ceramah dan diskusi. Pendekatan dilakukan dengan mencari permasalahan siswa/i dan memberi solusi. Kegiatan dimulai dengan ceramah hal-hal penting terkait gadget, narkoba dan pergaulan bebes ditambah dengan dampak dan cara penanggulangan. Permasalahan siswa/i diketahui ketika proses tanya jawab. Dari permasalahan yang muncul disusun hal-hal penting untuk kemudian diberikan solusi pada akhir acara.

\section{Hasil dan Pembahasan}

Kegiatan PKM ini dilaksanakan dalam bentuk ceramah dan tanya jawab terprogram. Rincian kegiatan diperlihatkan dalam tabel 1 di bawah ini.

Tabel 1 Rincian Kegiatan Sosialisasi pada siswa/i

\begin{tabular}{ll}
\hline \multicolumn{1}{c}{ Jadwal } & \multicolumn{1}{c}{ Kegiatan } \\
\hline $\begin{array}{l}\text { Sesi } 1 \\
08.00-09.30\end{array}$ & $\begin{array}{l}\text { Sosialisasi pengertian gadget dan pengertian narkoba secara spesifik serta } \\
\text { pergaulan bebas. }\end{array}$ \\
Sesi 2 & $\begin{array}{l}\text { Ceramah dan tanya jawab tentang gadget : pengertian, batasan waktu pemakaian } \\
\text { dan dampak yang ditimbulkan. }\end{array}$ \\
Sesi 3 & $\begin{array}{l}\text { Ceramah dan tanya jawab tentang narkoba : pengertian, jenis-jenis, bentuk-bentuk } \\
11.00-12.30\end{array}$ \\
\hline
\end{tabular}


Siswa/i SMP Abulyatama dalam hal ini bertindak sebagai peserta sosialisasi. Kegiatan ceramah dan tanya jawab berjalan lancar dengan suasana kondusif, Siswa/i dengan lugasnya menjawab pertanyaan dari pemateri sekali-kali disertai dengan guyon sehinggga suasana benar-benar kondusif. Para peserta yang terdiri dari siswa/i kelas VII s/d IX.

Hasil kegiatan dapat diidentifikasikan bahwa pengetahuan siswa/i tentang pemahaman gadget dan narkoba belum begitu maksimal terutama tentang lama penggunaan gadget yang baik dan benar serta dampak-dampak negatif yang ditimbulkan gadget apabila penggunaan/pemakaiannya secara berlebihan. Namun ada beberapa siswa/i yang sudah mengerti pemahaman dari kedua pokok bahasan materi.

Gadget adalah suatu peranti atau instrument yang memiliki tujuan dan fungsi praktis yang secara spesifik dirancang lebih canggih dibandingkan dengan teknologi yang diciptakan sebelumnya (Wikipedia, 2019). Siswa/i umumnya beranggapan bahwa penggunaan gadget tanpa adanya batasan waktu dan pernyataan itu tentu saja tidak benar dan dapat mengganggu keseimbangan kesehatan tubuh manusia. Keadaan ini dapat dihindari dengan cara penggunaan gadget yang tepat sesuai batasan waktu tertentu. Siswa/i SMP Abulyatama sudah paham bahaya narkoba tetapi mereka merasa pengaruh teman sangat berperan. Mereka mengetahui temanteman yang terlibat narkoba dan tidak mungkin menghindar untuk tidak berteman. Siswa/i SMP Abulyatama dengan mudah dapat melihat konten pornografi melalui HP, warnet dan tempattempat lain yang menyediakan layanan internet.

Setelah dilakukan pembekalan untuk meningkatkan pemahaman, siswa/i SMP Abulyatama sudah merasa puas. Hal-hal yang selama ini mereka pikirkan sudah terjawab. Hal ini mereka wujudkan dengan bersepakat untuk mulai melakukan hal-hal positif, memperbanyak kegiatan bermanfaat dan mendekatkan diri pada Allah SWT.

\section{Simpulan dan Rekomendasi}

Beberapa hal yang dapat disimpulkan dari kegiatan Pengabdian Kepada Masyarakat, sebagai berikut :

a) Siswa/i SMP Abulyatama telah memahami makna gadget, narkoba dan pergaulan bebas.

b) Siswa/i SMP Abulyatama telah memahami tentang waktu penggunaan gadget sesuai batasan usia.

c) Siswa/i SMP Abulyatama telah memahami jenis dan bentuk-bentuk dari narkoba, dampak negatif penggunaan narkoba tersebut.

d) Siswa/i di SMP Abulyatama telah memahami dampak pergaulan bebas.

e) Siswa/i di SMP Abulyatama setuju menggunakan gadget sesuai dengan batasan usia

f) Siswa/i di SMP Abulyatama setuju untuk tidak mendekati atau menggunakan narkoba sama sekali, cukup untuk dikenal dan dipahami. 
Siswa/i di SMP Abulyatama setuju dan sepakat untuk:

a) Memperbaiki Cara Pandang. Bersikap optimis dan hidup dalam kenyataan berusaha dan menerima hasil usaha walaupun tak sesuai dengan apa yang dinginkan sehingga apabila hasilnya mengecewakan dapat menanggapi dengan positif.

b) Jujur pada diri sendiri. Menyadari dan mengetahui apa yang terbaik untuk diri sehingga tidak menganiaya emosi dan diri sendiri.

c) Menanamkan nilai keislaman dalam diri. Meningkatkan keimanan sebagai pegangan dalam hidup.

d) Menjaga keseimbangan pola hidup. Melaksanakan manajemen waktu, emosi dan energi agar selalu berpikir positif dengan kegiatan positif setiap hari.

e) Banyak beraktivitas secara positif dan tidak memikirkan hal-hal negatif.

f) Berpikir akan masa depan. Menggapai cita-cita.

g) Mengurangi menggunakan gadget.

h) Selalu membaca buku.

i) Berkomunikasi baik dengan siapa saja.

j) Tidak mendekati pergaulan bebas.

\section{Acknowledgements}

Terima kasih Yayasan Universitas Abulyatama atas dukungan dana juga kepada LPPM Universitas Abulyatama yang sudah memfasilitasi publikasi kegiatan pengabdian masyarakat ini. Terima kasih kepada kepala sekolah, guru-guru dan siswa/i SMP Abulyatama.

\section{Daftar Pustaka}

Anggraeni, A., \& Hendrizal, H. (2018). Pengaruh Penggunaan Gadget Terhadap Kehidupan Sosial Para Siswa SMA. Jurnal PPKn \& Hukum, 13(1), 64-76.

Chusna, P. A. (2017). Pengaruh Media Gadget Pada Perkembangan Karakter Anak. Dinamika Penelitian: Media Komunikasi Sosial Keagamaan, 17(2), 315-330.

Eleanora, F. N. (2011). BahayaPenyalahgunaan narkoba Serta Usaha Pencegahan dan Penanggulangannya (Suatu Tinjauan Teoritis). Jurnal Hukum, 25(1), 439-452.

Kasim, F. (2014). Dampak Perilaku Seks Berisiko terhadap Kesehatan Reproduksi dan Upaya Penanganannya (Studi tentang Perilaku Seks Berisiko pada Usia Muda di Aceh). Jurnal Studi Pemuda, 3(1), 39-48.

Kompas. (2014). Memprihatinkan, Sisi Gelap Kehidupan ABG di Aceh. Kompas.COm. Retrieved from https://regional.kompas.com/read/2014/03/25/1213195/Memprihatinkan.Sisi .Gelap.Kehidupan.ABG.di.Aceh

Misran, M. (2019). Polres Aceh Besar Tangkap 10 Pengguna dan Bandar Narkoba, Ini Jumlah Sabu yang Ditemukan. Retrieved July 12, 2019, from https://aceh.tribunnews.com/2019/01/22/polres-aceh-besar-tangkap-10pengguna-dan-bandar-narkoba-ini-jumlah-sabu-yang-ditemukan

Molida, A. (2018). Pergaulan Bebas di Aceh Kian Memprihatinkan. Berita Kini.Co. Retrieved from http://beritakini.co/news/pergaulan-bebas-di-aceh-kian- 
Jurnal Pengabdian Kepada Masyarakat

memprihatinkan/index.html

Pina, N., \& Soedirham, O. (2015). Dukungan Pemerintah Dalam Mencegah Penyalahgunaan Narkoba Di Kota Surabaya. Jurnal Promkes, 3(2), 171-182.

Wikipedia. (2019). Gawai. Retrieved from https://id.wikipedia.org/wiki/Gawai

Witarsa, R., Hadi, R. S. M., Nurhananik, N., \& Haerani, N. R. (2018). Pengaruh Penggunaan Gadget Terhadap Kemampuan Interaksi Sosial Siswa Sekolah Dasar. Pedagogik, 6(1), 9-20. 